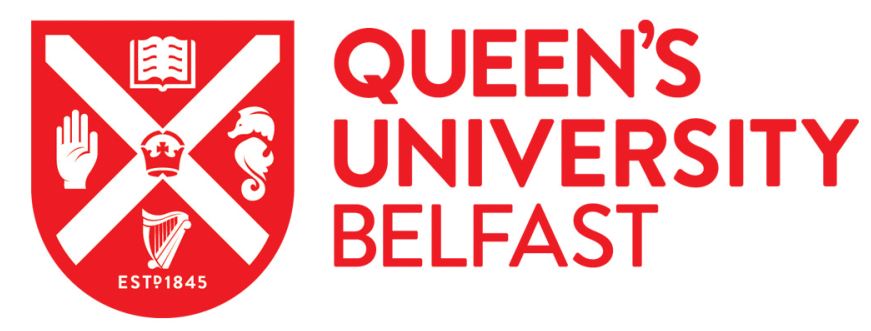

\title{
The structure of the Statistics Anxiety Rating Scale: A confirmatory factor analysis using UK psychology students
}

Hanna, D., Shevlin, M., \& Dempster, M. (2008). The structure of the Statistics Anxiety Rating Scale: A

confirmatory factor analysis using UK psychology students. Personality and Individual Differences, 45(1), 65-74. https://doi.org/10.1016/j.paid.2008.02.021

Published in:

Personality and Individual Differences

Document Version:

Publisher's PDF, also known as Version of record

Queen's University Belfast - Research Portal:

Link to publication record in Queen's University Belfast Research Portal

\section{General rights}

Copyright for the publications made accessible via the Queen's University Belfast Research Portal is retained by the author(s) and / or other copyright owners and it is a condition of accessing these publications that users recognise and abide by the legal requirements associated with these rights.

Take down policy

The Research Portal is Queen's institutional repository that provides access to Queen's research output. Every effort has been made to ensure that content in the Research Portal does not infringe any person's rights, or applicable UK laws. If you discover content in the Research Portal that you believe breaches copyright or violates any law, please contact openaccess@qub.ac.uk. 


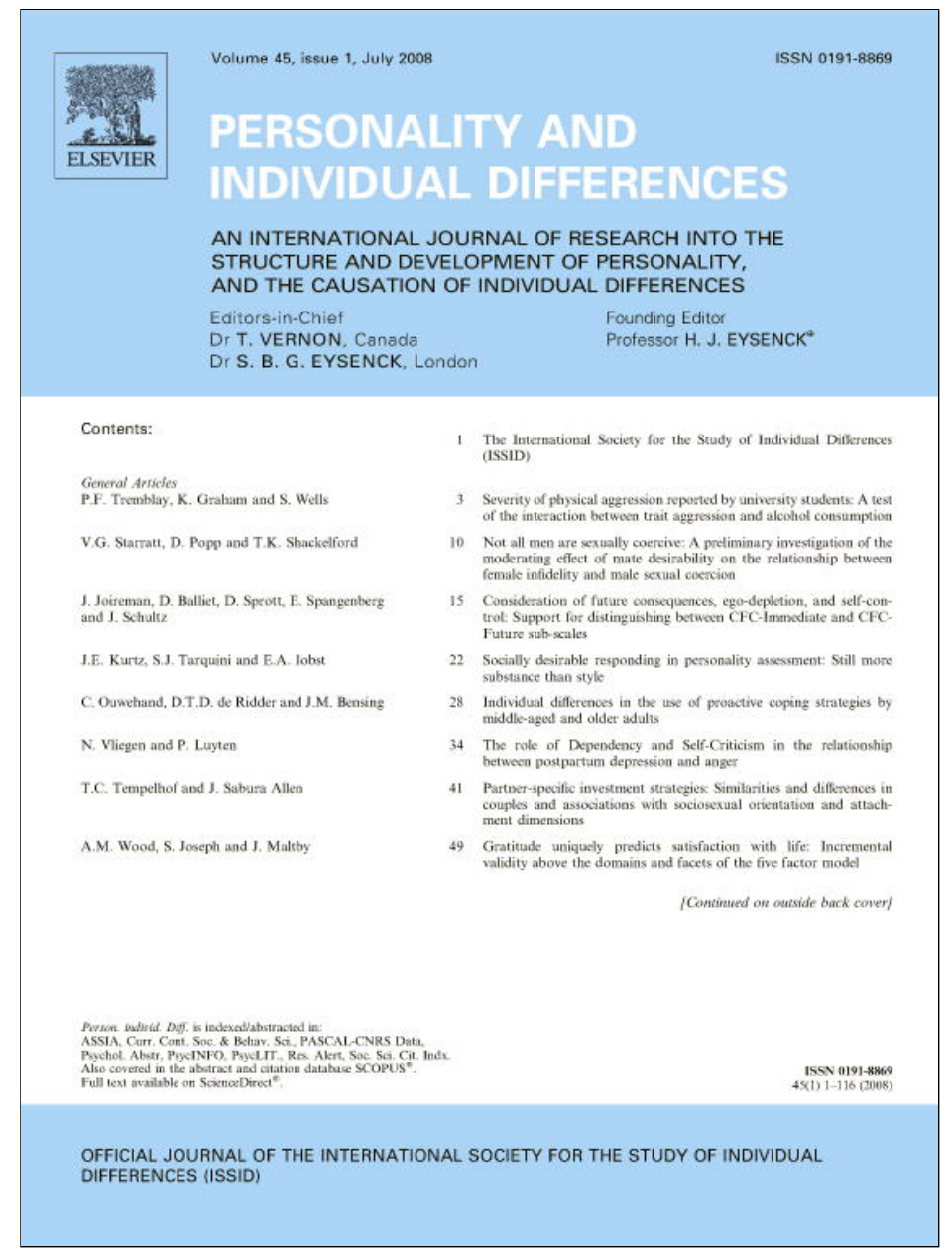

This article appeared in a journal published by Elsevier. The attached copy is furnished to the author for internal non-commercial research and education use, including for instruction at the authors institution and sharing with colleagues.

Other uses, including reproduction and distribution, or selling or licensing copies, or posting to personal, institutional or third party websites are prohibited.

In most cases authors are permitted to post their version of the article (e.g. in Word or Tex form) to their personal website or institutional repository. Authors requiring further information regarding Elsevier's archiving and manuscript policies are encouraged to visit:

http://www.elsevier.com/copyright 


\title{
The structure of the statistics anxiety rating scale: A confirmatory factor analysis using UK psychology students
}

\author{
Donncha Hanna $^{\mathrm{a}, *}$, Mark Shevlin ${ }^{\mathrm{b}}$, Martin Dempster ${ }^{\mathrm{a}}$

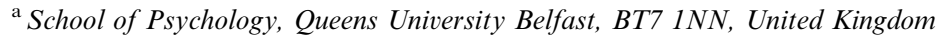 \\ ${ }^{\mathrm{b}}$ School of Psychology, University of Ulster, Magee Campus, BT48 7JL, United Kingdom
}

Received 3 August 2007; received in revised form 13 February 2008; accepted 26 February 2008

\begin{abstract}
This study aimed to examine the structure of the statistics anxiety rating scale. Responses from 650 undergraduate psychology students throughout the UK were collected through an on-line study. Based on previous research three different models were specified and estimated using confirmatory factor analysis. Fit indices were used to determine if the model fitted the data and a likelihood ratio difference test was used to determine the best fitting model. The original six factor model was the best explanation of the data. All six subscales were intercorrelated and internally consistent. It was concluded that the statistics anxiety rating scale was found to measure the six subscales it was designed to assess in a UK population.
\end{abstract}

(C) 2008 Elsevier Ltd. All rights reserved.

Keywords: Statistics anxiety; Statistical attitudes; Confirmatory factor analysis; STARS

\section{Introduction}

The importance of statistics and research methods in the undergraduate Psychology degree programme has been acknowledged by both the Quality Assurance Agency for Higher Education (2002) and the British Psychological Society (2006) within the UK. Students undertaking these subjects learn both subject specific skills and generic, transferable skills. For example, it has been demonstrated that the statistics element of the psychology undergraduate programme enhances critical reasoning (Lawson, 1999; Lehman and Nisbett, 1990; VanderStoep and Shaughnessy, 1997). However, empirical evidence and commonly held subjective opinion suggest statistics is one of the students' most disliked subjects (Sciutto, 1995). In fact, if the majority of psychology students could choose to drop one required course from their curriculum it would be statistics (Conners, McCown, and Roskos-Ewoldsen, 1998). This is supported by literature which suggests that up to $80 \%$ of

\footnotetext{
${ }^{*}$ Corresponding author. Tel.: +44 2890 975549; fax: +44 2890664144 E-mail address: donncha.hanna@qub.ac.uk (D. Hanna).
}

students experience 'statistic anxiety' (Onwuegbuzie and Wilson, 2003).

Statistics anxiety has been defined as the specific feelings of anxiety students experience when they encounter statistics, for example, gathering, processing and interpreting data (Cruise, Cash, and Bolton, 1985; Onwugbuzie, Da Ros, and Ryan, 1997). It could be argued that students experience anxiety with regards to many different aspects of their course (which will differ between students depending on their individual abilities and preferences) and indeed some anxiety is unavoidable as part of the assessment processes in higher education. However, studies have consistently demonstrated a negative relationship between statistics anxiety and performance (Benson, 1989; Feinberg and Halperin, 1978; Lalonde and Gardner, 1993; Onwuegbuzie and Daly, 1996; Onwuegbuzie and Seaman, 1995; Pretorius and Norman, 1992; Tremblay, Gardner, and Heipel, 2000; Zeidner, 1991). It has even been postulated that this anxiety is the best predictor of achievement in statistic courses (Fitzgerald, Jurs, and Hudson, 1996) and research methods courses (Onwuegbuzie, 2004). Furthermore, statistical anxiety has been shown to be 
related to increased levels of academic procrastination (Onwuegbuzie, 2004). This body of research has demonstrated the importance of statistical anxiety; therefore, it is imperative to have a valid assessment tool to assess this concept to ascertain if students are experiencing statistical anxiety, if it is impacting on their performance and to evaluate potential interventions to reduce such anxiety.

The statistical anxiety rating scale or STARS developed by Cruise et al. (1985) is currently the most widely used measure for assessing statistics anxiety (Onwuegbuzie and Wilson, 2003). Cruise et al. (1985) utilized principal components analysis to identify six components of statistics anxiety which the STARS purports to measure; these are: worth of statistics, interpretation anxiety, test and class anxiety, computational self-concept, fear of asking for help and fear of statistics teachers. However, some of the items within the STARS may not be suitable for a UK population and the factor structure has not been confirmed.

Table 1

The STARS questionnaire

\begin{tabular}{|c|c|}
\hline No. & Item \\
\hline 1 & Studying for an examination in a statistics course \\
\hline 2 & Interpreting the meaning of a table in a journal article \\
\hline 3 & Going to ask my statistics teacher for individual help with material I am having difficulty understanding \\
\hline 4 & Doing the coursework for a statistics course \\
\hline 5 & Making an objective decision based on empirical data \\
\hline 6 & Reading a journal article that includes some statistical analyses \\
\hline 7 & Trying to decide which analysis is appropriate for my research project \\
\hline 8 & Doing an examination in a statistics course \\
\hline 9 & Reading an advertisement for a car which includes figures on miles per gallon, depreciation, etc \\
\hline 10 & Walking into the room to take a statistics test \\
\hline 11 & Interpreting the meaning of a probability value once I have found it \\
\hline 12 & Arranging to have a body of data put into the computer \\
\hline 13 & Finding that another student in class got a different answer than I did to a statistical problem \\
\hline 14 & Determining whether to reject or retain the null hypothesis \\
\hline 15 & Waking up in the morning on the day of a statistics test \\
\hline 16 & Asking one of your lecturers for help in understanding a printout \\
\hline 17 & Trying to understand the odds in a lottery \\
\hline 18 & Watching a student search through a load of computer printouts from his/her research \\
\hline 19 & Asking someone in the computer lab for help in understanding a printout \\
\hline 20 & Trying to understand the statistical analyses described in the abstract of a journal article \\
\hline 21 & Enrolling in a statistics course \\
\hline 22 & Going over a final examination in statistics after it has been marked \\
\hline 23 & Asking a fellow student for help in understanding a printout \\
\hline 24 & I am a subjective person, so the objectivity of statistics is inappropriate for me \\
\hline 25 & I have not done maths for a long time. I know I will have problems getting through statistics \\
\hline 26 & I wonder why I have to do all these things in statistics when in actual life I will never use them \\
\hline 27 & Statistics is worthless to me since it is empirical and my area of specialization is abstract \\
\hline 28 & Statistics takes more time than it is worth \\
\hline 29 & I feel statistics is a waste \\
\hline 30 & Statistics teachers are so abstract they seem inhuman \\
\hline 31 & I cannot even understand secondary school maths; how can I possibly do statistics? \\
\hline 32 & Most statistics teachers are not human \\
\hline 33 & I lived this long without knowing statistics, why should I learn it now? \\
\hline 34 & Since I have never enjoyed maths I do not see how I can enjoy statistics \\
\hline 35 & I do not want to learn to like statistics \\
\hline 36 & Statistics is for people who have a natural leaning toward maths \\
\hline 37 & Statistics is a pain I could do without \\
\hline 38 & I do not have enough brains to get through statistics \\
\hline 39 & I could enjoy statistics if it were not so mathematical \\
\hline 40 & I wish the statistics requirement would be removed from my academic program \\
\hline 41 & I do not understand why someone in my field needs statistics \\
\hline 42 & I do not see why I have to fill my head with statistics. It will have no use in my career \\
\hline 43 & Statistics teachers speak a different language \\
\hline 44 & Statisticians are more number oriented than they are people oriented \\
\hline 45 & I cannot tell you why, but I just do not like statistics \\
\hline 46 & Statistics teachers talk so fast you cannot logically follow them \\
\hline 47 & Statistical figures are not fit for human consumption \\
\hline 48 & Statistics is not really bad. It is just too mathematical \\
\hline 49 & Affective skills are so important in my (future) profession that I do not want to clutter my thinking with something as cognitive as statistics \\
\hline 50 & I am never going to use statistics so why should I have to take it? \\
\hline 51 & I am too slow in my thinking to get through statistics \\
\hline
\end{tabular}


Baloglu (2002) conducted the only attempt to confirm the six factor structure of the STARS in American college students however this analysis appears to have been conducted on scale scores rather than item scores; effectively demonstrating the six factors did not form a high order structure (on the assumption that the six factors are structurally valid). For completeness, this study assessed not only the six factor model but one and four factor models also. The high internal consistency of the total 51 item scale reported by Onwuegbuzie (1993) and Baloglu (2002), both reported $\alpha=0.96$, may suggest the STARS is a uni-dimensional scale. Additionally, Onwugbuzie et al. (1997) conducted focus groups which suggested there were four main elements to statistics anxiety.

The aim of this article was to test the factor structure of the STARS questionnaire for a UK population. In addition to the unconfirmed six-factor model, one- and four- factor models will also be assessed. If either of the multi-factorial models is found to be acceptable an additional second order model will be tested to determine if

Table 2

The original and revised items in the STARS questionnaire

\begin{tabular}{|c|c|c|}
\hline No. & Version & Item \\
\hline \multirow[t]{2}{*}{4} & Original & Doing the homework for a statistics course \\
\hline & Revised & Doing the coursework for a statistics course \\
\hline \multirow[t]{2}{*}{9} & Original & $\begin{array}{l}\text { Reading an advertisement for an automobile which } \\
\text { includes figures on gas mileage, compliance with } \\
\text { population regulations, etc }\end{array}$ \\
\hline & Revised & $\begin{array}{l}\text { Reading an advertisement for a car which includes } \\
\text { figures on miles per gallon, deprecation, etc. }\end{array}$ \\
\hline \multirow[t]{2}{*}{10} & Original & Walking into the classroom to take a statistics test \\
\hline & Revised & Walking into the room to take a statistics test \\
\hline \multirow[t]{2}{*}{16} & Original & $\begin{array}{l}\text { Asking one of your professors for help in understanding } \\
\text { a printout }\end{array}$ \\
\hline & Revised & $\begin{array}{l}\text { Asking one of your lecturers for help in understanding a } \\
\text { printout }\end{array}$ \\
\hline \multirow[t]{2}{*}{25} & Original & $\begin{array}{l}\text { I have not had math for a long time. I know I will have } \\
\text { problems getting through statistics }\end{array}$ \\
\hline & Revised & $\begin{array}{l}\text { I have not done maths for a long time. I know I will have } \\
\text { problems getting through statistics }\end{array}$ \\
\hline \multirow[t]{2}{*}{31} & Original & $\begin{array}{l}\text { I cannot even understand seventh- and eighth-grade } \\
\text { math; how can I possibly do statistics }\end{array}$ \\
\hline & Revised & $\begin{array}{l}\text { I cannot even understand secondary school maths; how } \\
\text { can I possibly do statistics }\end{array}$ \\
\hline
\end{tabular}

the first order factors can be explained by a higher order general factor representing statistics anxiety.

\section{Methods}

\subsection{Participants}

The STARS questionnaire was made available on-line and universities throughout the UK that offered undergraduate psychology courses were invited to inform their students about the study. A total of 849 participants completed the questionnaire during the 3 weeks it was available on-line during May 2007. As 199 of the participants did not complete all 51 items in the STARS questionnaire the sample size used for analysis in this study was reduced to 650 . These students constituted approximately $12.7 \%$ of the total UK psychology undergraduate population and represented 31 different universities. The mean age was 22 years $(\mathrm{SD}=5.44)$ and ranged from 18 to 56 . The majority of the participants were female $(n=533 ; 82 \%)$; this is reflective of gender split in the total UK population where approximately $79 \%$ of the students are female. The students were relatively evenly distributed with regards to the progression through their course; $31.1 \%$ were in first year, $31.7 \%$ were in second year, 26\% were in third year and $6.3 \%$ were in their fourth year. Additionally three students indicated they were part-time and $29(4.5 \%)$ did not answer this question.

\subsection{Measures}

The data was collected using a set of demographic questions and the STARS questionnaire. These were made available on-line. The STARS is a 51 item questionnaire with responses gathered on a 5 point Likert scale (see Table 1). The rubric asked participants to indicate how much anxiety they would experience (from no anxiety to strong anxiety) in each of the situations for the first 23 items and then the participants were asked their level of agreement (from strongly agree to strongly disagree) on the remaining 28 items. Higher scores on an item or subscale indicate higher levels of that attitude or anxiety except for the 'fear of statistics teachers' subscale where higher scores indicate lower levels of anxiety or more

Table 3

Fit indices for the alternative models of the STARS questionnaire

\begin{tabular}{lllll}
\hline Item & Model 1 1-factor & Model 2 4-factor & Model 3 6-factor & Model 4 6-factor with second order factor \\
\hline S-B $\chi^{2}$ & $13,448.90$ & 5939.86 & 4218.67 & 4391.75 \\
$d f(p)$ & $1224(.00)$ & $1218(.00)$ & $1209(.00)$ & $1218(.00)$ \\
RMSEA 90\% CI & $.12(.12-.13)$ & $.077(.075-.079)$ & $.062(.060-.064)$ & $.0630 .061-.065)$ \\
ECVI 90\% CI & $23.96(20.47-21.62)$ & $10.72(9.12-9.86)$ & $7.74(6.56-7.17)$ & $7.10(6.79-7.42)$ \\
IFI & .87 & .95 & .97 & .97 \\
CFI & .87 & .95 & .97 & .97 \\
SRMR & .091 & .072 & .068 & .110 \\
\hline
\end{tabular}

Note: $\mathrm{S}-\mathrm{B} \chi^{2}$, Satorra-Bentler scaled $\chi^{2}$; RMSEA, root mean square error of approximation; CI, confidence intervals; ECVI, expected cross validation index; IFI, incremental fit index; CFI, comparative fit index; SRMR, standardised root mean residual. 
positive attitudes. Each of the six subscales purports to measure a different aspect of statistical anxiety. These scales demonstrated 5-week test-retest reliabilities between .67 and .83 and concurrent validity was claimed as strong positive correlations were evident with the mathematics anxiety scale (Cruise et al., 1985). The 'worth of statistics' subscale attempts to measure the perceived usefulness of statistics. The 'interpretation anxiety' subscale attempts to measure anxiety when interpreting statistical results. 'Test and class anxiety' is designed to assess the anxiety experienced when taking a statistics test or attending a statistics class. The 'computation self-concept' subscale is related to a person's self-belief in their ability to cope with the calculations and mathematics related to statistics. The 'ask for help' subscale attempts to assess the anxiety experienced when an individual intends to ask for help on a statistical problem. The final subscale, 'fear of statistics teachers', claims to measure students' perceptions of their statistic teachers. However, during piloting of the STARS with staff and postgraduate students to ensure the items could be easily read and understood at Queens University Belfast it became apparent that the language used in six of items was not appropriate for UK students (see Table 2). These six items were revised slightly so they could be more readily understood by UK students; for example the word 'automobile' was changed to 'car'.

\subsection{Analysis}

Three confirmatory factor models were specified and estimated using LISREL 8.72 (Jöreskog and Sörbom, 2005a). A covariance matrix and an asymptotic weight matrix were computed using PRELIS 2.72 (Jöreskog and Sörbom, 2005b) based on the 51 items of the STARS questionnaire and the model parameters estimated using maximum likelihood. All factors were allowed to correlate and no correlated errors were included in any of the models. The use of an asymptotic weight matrix allows for weaker assumptions regarding the distribution of the observed variables and results in improved fit and test statistics (Satorra, 1992; Curran, West, and Finch, 1996).

Following the guidelines suggested by Hoyle and Panter (1995) the goodness of fit for each model was assessed using a range of fit indices including the Satorra-Bentler scaled chi-square $\left(\mathrm{S}-\mathrm{B} \chi^{2}\right)$, the incremental fit index (IFI: Bollen, 1989), and the comparative fit index (CFI: Bentler, 1990). A non-significant $\chi^{2}$, and values greater than .95 for the IFI and CFI are considered to reflect acceptable model fit. In addition, the root mean square error of approximation (RMSEA: Steiger, 1990) with 90\% confidence intervals $(90 \%$ CI $)$ were reported, where a value less than.05 indicates close fit and values up to .08 indicating reasonable errors of approximation in the population (Jöreskog and Sörbom, 1993). The standardized root-mean-square residual (SRMR: Jöreskog and Sörbom, 1981) has been shown to be sensitive to model mis-specification and its use recommended by $\mathrm{Hu}$ and Bentler (1999). Values less than .08 are considered to be indicative of acceptable model fit ( $\mathrm{Hu}$ and Bentler, 1999). The comparative fit of the models was assessed using the expected cross validation index (ECVI; Browne and Cudeck, 1989), an index used for the purposes of model comparison, with the smallest value being indicative of the best fitting model.

Table 4

Standardised factor loadings for the 6-factor model of the STARS questionnaire

\begin{tabular}{|c|c|c|c|c|c|c|}
\hline & Test & Interpretation & $\begin{array}{l}\text { Ask for } \\
\text { help }\end{array}$ & Worth & Teacher & $\begin{array}{l}\text { Self- } \\
\text { concept }\end{array}$ \\
\hline Q1 & .81 & & & & & \\
\hline Q4 & .64 & & & & & \\
\hline Q8 & .81 & & & & & \\
\hline Q10 & .74 & & & & & \\
\hline Q13 & .55 & & & & & \\
\hline Q15 & .74 & & & & & \\
\hline Q21 & .64 & & & & & \\
\hline Q22 & .57 & & & & & \\
\hline Q2 & & .66 & & & & \\
\hline Q5 & & .72 & & & & \\
\hline Q6 & & .72 & & & & \\
\hline Q7 & & .60 & & & & \\
\hline Q9 & & .46 & & & & \\
\hline Q11 & & .71 & & & & \\
\hline Q12 & & .55 & & & & \\
\hline Q14 & & .67 & & & & \\
\hline Q17 & & .42 & & & & \\
\hline Q18 & & .54 & & & & \\
\hline Q20 & & .75 & & & & \\
\hline Q3 & & & .85 & & & \\
\hline Q16 & & & .94 & & & \\
\hline Q19 & & & .68 & & & \\
\hline Q23 & & & .48 & & & \\
\hline Q24 & & & & .52 & & \\
\hline Q26 & & & & .73 & & \\
\hline Q27 & & & & .71 & & \\
\hline Q28 & & & & .76 & & \\
\hline Q29 & & & & .81 & & \\
\hline Q33 & & & & .78 & & \\
\hline Q35 & & & & .63 & & \\
\hline Q36 & & & & .51 & & \\
\hline Q37 & & & & .74 & & \\
\hline Q40 & & & & .80 & & \\
\hline Q41 & & & & .68 & & \\
\hline Q42 & & & & .81 & & \\
\hline Q45 & & & & .60 & & \\
\hline Q47 & & & & .67 & & \\
\hline Q49 & & & & .74 & & \\
\hline Q50 & & & & .85 & & \\
\hline Q30 & & & & & .77 & \\
\hline Q32 & & & & & .66 & \\
\hline Q43 & & & & & .80 & \\
\hline Q44 & & & & & .60 & \\
\hline Q46 & & & & & .71 & \\
\hline Q25 & & & & & & .58 \\
\hline Q31 & & & & & & .73 \\
\hline Q34 & & & & & & .75 \\
\hline Q38 & & & & & & .80 \\
\hline Q39 & & & & & & .67 \\
\hline Q48 & & & & & & .51 \\
\hline Q51 & & & & & & .80 \\
\hline
\end{tabular}

Note: All factor loadings significant $(p<.05)$. 
Table 5

Inter-factor correlations and descriptive statistics

\begin{tabular}{|c|c|c|c|c|c|c|}
\hline & Test & Interpretation & Ask for help & Worth & Teacher & Self-concept \\
\hline Interpretation & 0.68 & & & & & \\
\hline Ask for help & 0.44 & 0.46 & & & & \\
\hline Worth & -0.54 & -0.54 & -0.34 & & & \\
\hline Teacher & -0.50 & -0.42 & -0.47 & 0.66 & & \\
\hline Self-concept & -0.67 & -0.60 & -0.41 & 0.76 & 0.66 & \\
\hline Cronbach's alpha & .87 & .87 & .83 & .94 & .83 & .87 \\
\hline Mean score & 27.07 & 30.26 & 10.39 & 56.98 & 18.2 & 23.91 \\
\hline Standard deviation & 6.69 & 8.42 & 3.87 & 14.13 & 4.72 & 6.60 \\
\hline Range & $8-40$ & $11-53$ & $4-20$ & $17-80$ & $5-25$ & $9-35$ \\
\hline Potential range & $8-40$ & $11-55$ & $4-20$ & $16-80$ & $5-25$ & $7-35$ \\
\hline
\end{tabular}

\section{Results}

\subsection{Confirmatory factor analysis and reliability analysis}

The fit indices for the three models are reported in Table 3.

The fit indices showed that a 1-factor model was a poor model and was rejected. On the basis of meeting the criteria associated with the RMSEA, IFIF, CFI and the SRMR both the 4-factor and 6-factor models were judged to exhibit reasonable model fit, but all the fit indices indicated that the 6-factor model was a better model. The ECVI for the 6factor model was the lowest. The 4- and 6-factor models are nested so a likelihood ratio difference test ${ }^{1}$ is possible to determine statistical difference between the fit of the models. The 6-factor model was a significantly better explanation of the data than Model $1\left(\Delta \mathrm{S}-\mathrm{B} \chi^{2}=1645.74\right.$, $\mathrm{df}=9, p<.05)$. Although the chi-square for these models were large relative to the degrees of freedom, and statistically significant, this should not lead to the rejection of the models as the large sample size increases the power of the test (Tanaka, 1987). The increased power of the chisquare test can result in models with no serious mis-specification being rejected as minor discrepancies between the sample and implied covariance matrix are detected. On the basis of this it is proposed that the 6-factor represents an adequate description of the data, and is judged the best of the alternative models. This model was re-specified to include a single second order factor (Model 4). All first order factors were specified to load on the second order factor. The fit indices are reported in Table 3. The fit of this model was acceptable on the basis of the RMSEA, IFI, and CFI and the ECVI was lower than for Model 3. However, the SRMR was relatively high and the likelihood ratio difference test indicated that Model 3 provided a significantly better explanation of the sample data $\left(\Delta \mathrm{S}-\mathrm{B} \chi^{2}=73.08\right.$, $\mathrm{df}=9, \quad p<.05)$. The standardized factor loadings for Model 3 are presented in Table 4. All loadings were statistically significant $(p<0.05)$.

The factor correlations and estimates of reliability (Cronbach's alpha) are reported in Table 5.

\footnotetext{
${ }^{1}$ Satorra and Bentler (2001) have developed a scaled difference chisquare statistic to compare the $\mathrm{S}-\mathrm{B} \chi^{2}$ for nested models.
}

All factor correlations were statistically significant $(p<.05)$. The estimates of reliability were all high and ranged from $\alpha=.83$ (Ask for Help) to $\alpha=.94$ (Worth).

\section{Discussion}

This article tested a series of alternative factor structures of the STARS based on a sample of UK undergraduate psychology students. Three alternative methods were specified and tested. On the basis of the fit indices, a six-factor model was considered to be the best explanation of the data. This model was based of the original structure proposed by Cruise et al. (1985) although six of the items were revised to be more suitable for the UK population. The standardized factor loadings were all positive and statistically significant, ranging from 0.42 to 0.94 . Each of the six subscales demonstrated high levels of internal consistency ranging from 0.83 to 0.94 . These internal consistency figures compare favorably with previous research which found a range between 0.68 and 0.94 (Cruise et al., 1985), 0.83 and 0.92 (Onwuegbuzie, 1993), 0.80 and 0.84 (Onwuegbuzie, 1998) or 0.64 and 0.96 (Baloglu, 2003). The fact the intercorrelations indicated positive and negative directional relationships reflected the way in which the subscales were scored. Higher scores on interpretation anxiety, test and class anxiety and fear of asking for help indicated higher anxiety or more negative attitudes. Higher scores on worth of statistics, interpretation anxiety, and fear of statistics teachers indicated more positive attitudes or lower anxiety. Researchers using the scale should endeavor to administer the full questionnaire and report the scores of all six of these subscales. It should be noted that many of the items and subscales do not appear to measure statistical anxiety directly but related concepts, for example, views on the worth of statistics. This was substantiated by the correlated six first order factor model (Model 3) being found to be a significantly better model than the second order model (Model 4), where all first order factors loaded on a single second order factor, Therefore it is suggested that the term 'statistical attitudes and anxiety' is a more appropriate label for the concept currently referred to as statistical anxiety.

The findings of the research are consistent with exploratory factor analysis conducted on the STARS among a 
sample of students from the USA (the only previously conducted factor analysis of the STARS). Therefore, it appears that there are no differences in the structure of statistical attitudes and anxiety among students in the UK and USA. However, comparing the mean scores on each of the STARS scales found in the present study with scores obtained from samples in the USA (Baloglu, 2003; D'Andrea and Waters, 2002), the present sample had notably more negative scores on the worth of statistics and computation self-concept scales. This suggests that the sample in the present study were less likely to recognize the value of statistics and more likely to have low computational self-concept. It is possible that this may be a result of geographical/cultural differences or that the present study was restricted to psychology students. Further work with students from a broader range of disciplines in the UK is required to investigate these differences.

In conclusion, the STARS was found to measure the six internally consistent factors it had been designed to assess in a sample of UK undergraduate psychology students. Future research could establish the temporal stability of the six-factor model, and its invariance across groups (educational, cultural, or gender). In addition, the robustness of the reported solution could be examined by using alternative measures of association (e.g. polychoric correlations) and estimators (e.g. mean and variance adjusted weighted least squares estimation).

\section{Acknowledgements}

The authors would like to thank Geoffrey Caves for his invaluable assistance with creating the webpage and on-line data collection. We would also like to acknowledge David Rugerri for his help contacting various universities.

\section{References}

Baloglu, M. (2002). Psychometric properties of the statistics anxiety rating scale. Psychological Reports, 90, 315-325.

Baloglu, M. (2003). Individual differences in statistics anxiety among college students. Personality and Individual Differences, 34, 855-865.

Benson, J. (1989). Structural components of statistical test anxiety in adults: An exploratory model. Journal of Experimental Education, 57, 247-261.

Bentler, P. M. (1990). Comparative fit indices in structural models. Psychological Bulletin, 107, 238-246.

Bollen, K. A. (1989). Structural equations with latent variables. New York: Wiley.

British Psychological Society (2006). Regulations and reading lists for the qualifying exam. Leicester, UK: BPS.

Browne, M. W., \& Cudeck, R. (1989). Single sample cross-validation indices for covariation structures. Multivariate Behavioral Research, $24,445-455$.

Conners, F. A., McCown, S. M., \& Roskos-Ewoldsen, B. (1998). Unique challenges in teaching undergraduate statistics. Teaching of Psychology, 25, 40-42.

Cruise, R. J., Cash, R. W., \& Bolton, D. L. (1985). Development and validation of an instrument to measure statistical anxiety. In Paper presented at the proceedings of the American Statistical Association.
Curran, P. J., West, S. G., \& Finch, J. F. (1996). The robustness of test statistics to nonnormality and specification error in confirmatory factor analysis. Psychological Methods, 1, 16-29.

D'Andrea, L. \& Waters, C. (2002). Teaching statistics using short stories: Reducing anxiety and changing attitudes. In Proceedings of the sixth international conference on teaching statistics.

Feinberg, L. B., \& Halperin, S. (1978). Affective and cognitive correlates of course performance in introductory statistics. Journal of Experimental Education, 46, 11-18.

Fitzgerald, S. M., Jurs, S., \& Hudson, L. M. (1996). A model predicting statistics achievement among graduate students. College Student Journal, 30, 361-366.

Hoyle, R. H., \& Panter, A. T. (1995). Writing about structural equation models. In R. H. Hoyle (Ed.). Structural equation modeling: Concepts, issues and applications. London: Sage.

Hu, L., \& Bentler, P. M. (1999). Cutoff criteria for fit indexes in covariance structure analysis: Conventional criteria versus new alternatives. Structural Equation Modeling, 6, 1-55.

Jöreskog, K., \& Sörbom, D. (1981). LISREL V: Analysis of linear structural relationships by the method of maximum likelihood. Chicago: National Educational Resources.

Jöreskog, K., \& Sörbom, D. (1993). Structural equation modeling with the SIMPLIS command language. Chicago: Scientific Software.

Jöreskog, K., \& Sörbom, D. (2005a). LISREL 8.72. Chicago: Scientific Software.

Jöreskog, K., \& Sörbom, D. (2005b). PRELIS 2.72. Chicago: Scientific Software.

Lalonde, R. N., \& Gardner, R. C. (1993). Statistics as a second language: Predicting performance of psychology students. Canadian Journal of Behavioral Science, 25, 108-125.

Lawson, T. J. (1999). Assessing psychological critical thinking as a learning outcome for psychology majors. Teaching of Psychology, 26(3), 207-209.

Lehman, D. R., \& Nisbett, R. E. (1990). A longitudinal study of the effects of undergraduate training on reasoning. Developmental Psychology, 26, 952-960.

Onwuegbuzie, A. J. (1993). The interaction of statistics test anxiety and examination condition in statistics achievement of post-baccalaureate non-statistics majors. Unpublished doctoral dissertation, The University of South Carolina.

Onwuegbuzie, A. J. (1998). The dimensions of statistics anxiety: A comparison of prevalence rates among mid-southern university students. Louisiana Educational Research Journal, 23, 23-40.

Onwuegbuzie, A. J. (2004). Academic procrastination and statistics anxiety. Assessment and Evaluation in Higher Education, 29, 3-19.

Onwuegbuzie, A. J., \& Daly, C. E. (1996). The relative contributions of examination - taking coping strategies and study copying strategies on test anxiety: A concurrent analysis. Cognitive Therapy and Research, $20,287-303$.

Onwuegbuzie, A. J., \& Seaman, M. A. (1995). The effect of time constraints and statistics test anxiety on test performance in a statistics course. Journal of Experimental Education, 62, 115-124.

Onwuegbuzie, A. J., \& Wilson, V. A. (2003). Statistics anxiety: Nature, etiology, antecedents, effects and treatments. Teaching in Higher Education, 8, 195-209.

Onwugbuzie, A. J., Da Ros, D., \& Ryan, J. M. (1997). The components of statistics anxiety: A phenomenological study. Focus on Learning Problems in Mathematics, 19(4), 11-35.

Pretorius, T. B., \& Norman, A. M. (1992). Psychometric data on the statistics anxiety scale for a sample of South African students. Educational and Psychological Measurement, 52, 933-937.

Quality Assurance for Higher Education (2002). Psychology. Gloucester: QAA.

Satorra, A. (1992). Asymptotic robust inferences in the analysis of mean and covariance structures. Sociological Methodology, 22, 249-278.

Satorra, A., \& Bentler, P. (2001). A scaled difference chi-square test statistic for moment structure analysis. Psychometrika, 66, 507-514. 
Sciutto, M. J. (1995). Student-centered methods for decreasing anxiety and increasing interest level in undergraduate statistics courses. Journal of Instructional Psychology, 22(3), $277-280$.

Steiger, J. H. (1990). Structural model evaluation and modification: An interval estimation approach. Multivariate Behavioral Research, 25, 173-180.

Tanaka, J. S. (1987). How big is big enough?: Sample size and goodness of fit in structural equation models with latent variables. Child Development, 58, 134-146.
Tremblay, P. F., Gardner, R. C., \& Heipel, G. (2000). A model of the relationships among measures of affect, aptitude, and performance in introductory statistics. Canadian Journal of Behavioural Science, 32(1), $40-48$.

VanderStoep, S. W., \& Shaughnessy, J. J. (1997). Taking a course in research methods improves reasoning about real-life events. Teaching of Psychology, 24, 122-124.

Zeidner, M. (1991). Statistics and mathematics anxiety in social science students: Some interesting parallels. British Journal of Educational Psychology, 61(3), 319-332. 